\title{
Rail Transport Infrastructure on the Example of Level Crossing System
}

\author{
Perzyński Tomasz $^{1}$, Wojciechowski Jerzy ${ }^{2}$, Lukasik Zbigniew ${ }^{3}$ \\ ${ }^{1,2,3}$ Kazimierz Pulaski University of Technology and Humanities in Radom \\ *Corresponding author E-mail: t.perzynski@uthrad.pl
}

\begin{abstract}
The paper presents an analysis of the system of automatic level crossing. The proposed system belongs to a group of linear devices that ensure safe movement of motor vehicles at intersections of railway and car roads. In the paper, the computational tasks were carried out. On the basis of statistical data, the THR rate, which is characteristic for rail transport, was estimated. An example of modeling railway automation systems based on Markov processes is also presented.
\end{abstract}

Keywords: level crossing system, models, safety, THR.

\section{Introduction}

Railway transport is one of the elements of the Polish transport system. In order to carry out transport tasks it is necessary to maintain the availability of rail infrastructure at a high level. This can be achieved through the diagnostics of devices responsible for controlling and managing the transport process and modernizing already existing systems. One of the elements of the railway infrastructure modernization is the need to maintain a high level of safety. It should be remembered, that the application of new solutions, including computer-aided ones, must meet the requirements of the safety stipulated in the standards. In the recent years, the Polish railways have tended to increase the number of installed computer-controlled railway traffic control systems, in particular in control districts. According to the data for 2016 [1], over 30\% of the systems at railway and roads junctions were modern systems equipped with self-diagnosis and event registration systems. The accession of Poland to the EU in 2004 resulted in obligatory application of standards related to the design, testing, implementation and maintenance of safe railway automation systems. One of the basic normative documents regarding system safety is the PNEN 50126-2 standard. This standard describes, in particular, safety-related generic aspects of the RAMS (Reliability, Availability, Maintainability and Safety), life-cycle and methods to derive the safety requirements for systems and subsystems, [2]. The solutions applied in Poland in relation to the data transmission medium are based mainly on the solutions of wired data transmission. PN-EN 50159-2 standard (Railway applications - Communication, signalling and processing systems - Safety-related communication in transmission systems) allows the use of wireless transmission. Transmission based on radio networks can be used when there is a technical problem of building a section of a traditional overhead line for technical reasons. Safety of transmission in computer control and management systems requires:

- high reliability,

- proper quality of connections and bandwidth,

- safety transmission, including cryptographic methods.
The article presents an example of a modern system of automatic crossing signaling, RASP-4F. Analytical tasks were also fulfilled based on the proposed mathematical model. On the basis of the statistical data, the safety parameters of the system of automatic crossing signaling have been determined. Based on the operation data, the $\chi 2$ test allowed not to reject the hypothesis, that the times of failures for the group of level crossing systems are related to the exponential distribution.

\section{Safety in the Railway Automation Systems}

Each contemporary system of railway traffic management and control must have documentation allowing the system to be operated on the railway line. Currently, the basic indicator necessary to assess railway automation systems is the acceptable level of risk THR (Tolerable Hazard Rate), determined as, [8]:

$T H R=\prod_{i=1}^{n} \frac{\lambda_{i}}{t_{d_{i}}{ }^{-1}} \cdot \sum_{i=1}^{n}{t_{d_{i}}}^{-1}$

where: $\lambda_{i}$ - failure rate, $t_{d_{i}}{ }^{-1}-$ safe down rate.

The recommended value of THR related to safety level SIL-4 is presented on Table 1.

Table 1: Value of THR, [10]

\begin{tabular}{|c|c|}
\hline THR & $\begin{array}{c}\text { SIL } \\
\text { (Safety Integrity Level) }\end{array}$ \\
\hline $10^{-9} \leq T H R<10^{-8}$ & 4 \\
\hline $10^{-8} \leq T H R<10^{-7}$ & 3 \\
\hline $10^{-7} \leq T H R<10^{-6}$ & 2 \\
\hline $10^{-6} \leq T H R<10^{-5}$ & 1 \\
\hline
\end{tabular}

For the "2z2" system, the formula (1) takes the form:

$T H R=\frac{\lambda_{A}}{t_{d_{A}}{ }^{-1}} \cdot \frac{\lambda_{B}}{t_{d_{B}}{ }^{-1}} \cdot\left(t_{d_{A}}{ }^{-1}+t_{d_{B}}{ }^{-1}\right)$ 
With respect to formula (1), the system safety depends not only on the intensity of failure, but also on the detection time of single and double damages.

\section{Linear Systems - Automatic Level Crossing System}

Rail linear systems are responsible for the implementation of train routes between railway posts. This group of devices includes line blocking systems (automatic blocking and semi-automatic blocking) or remote control devices. An example of a linear system is also automatic level crossing system, which is used to secure traffic on rail-road crossings, [4]. An example of the installed RASP$4 \mathrm{~F}$ system is shown in Figure 1.

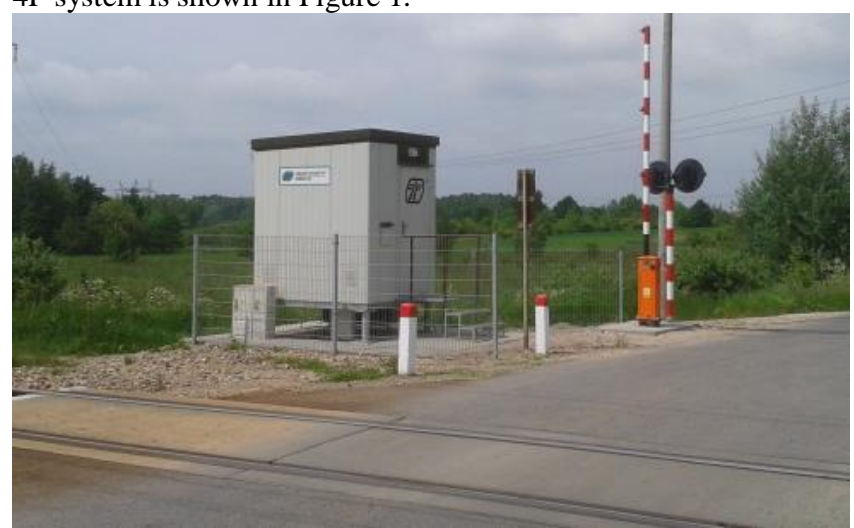

Fig. 1: RASP-4F system installed on railway line number 8, Poland (own study)

The basic elements of the laboratory testing system are presented in Fig. 2 (Faculty of Transport and Electrical Engineering, UTH Radom).

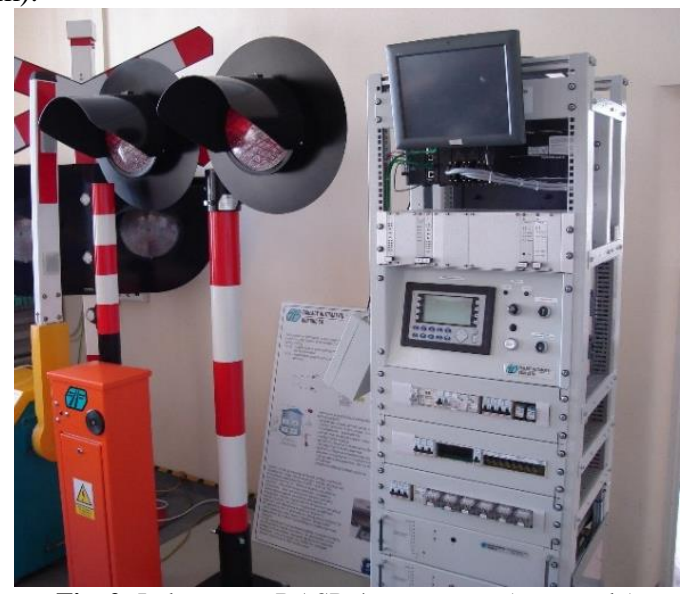

Fig. 2: Laboratory, RASP-4 test system (own study)

In the system shown in Fig. 1, train axle counters are used to detect track occupancy. The system includes, among others main container (RASP-KG - Fig. 1), apparatus cabinets and remote control unit. Automatic RASP-4F level crossing system is a type of device that uses a "2z2" redundant solution. To achieve a high level of safety of the RASP-4F system, redundancy was used in [4]:

- control devices together with the self-testing function,

- executive devices with the self-testing function,

- power devices.

In the event, when the axle sensors detect the presence of the train, the closing procedure of the gates is started. This closure takes place at least $30 \mathrm{~s}$ before the arrival of the train on the level crossing. The opening of the gates is $5 \mathrm{~s}$. after passing the last axle of the train. The scheme of cooperation of control systems in the system is shown in Fig. 3.

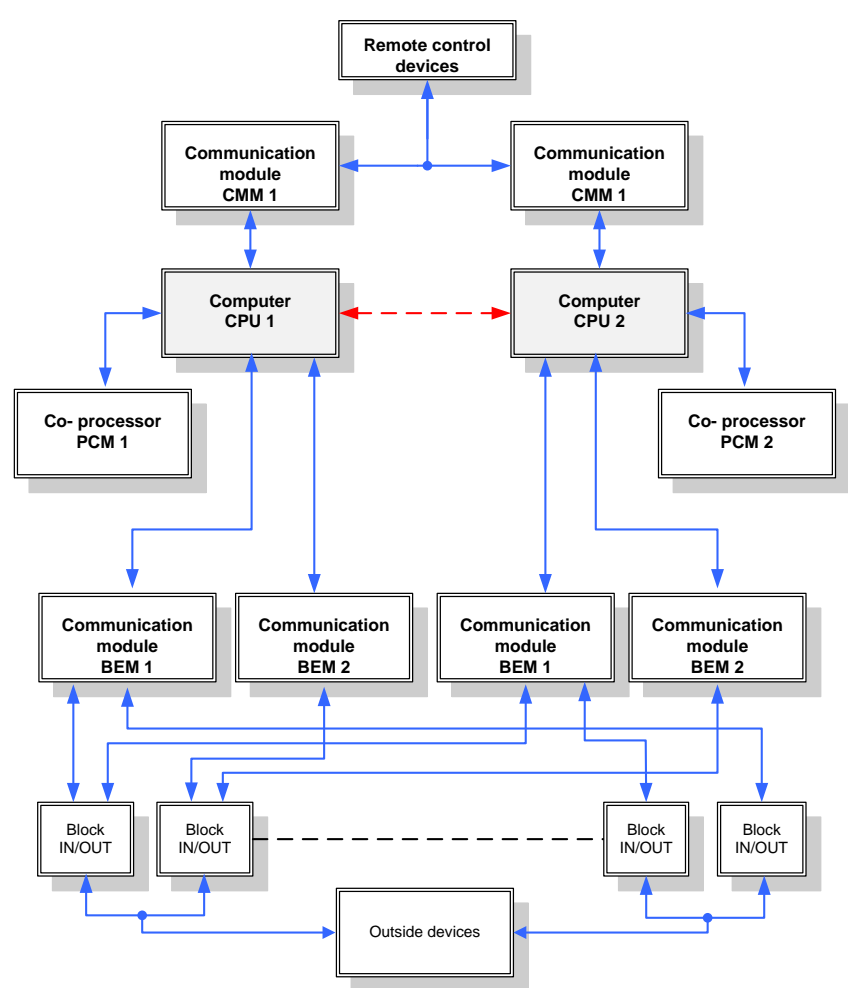

Fig. 3: RASP-4F - diagram of cooperation between control devices

The main container contains two PLCs, an operator terminal and an input / output card unit. The two independent CPUs controllers exchange data and work synchronously via the Ethernet bus. The operation of the system is supervised by the remote control device, which is the master controller. The RASP-4F system can cooperate with various stationary traffic management and control systems. The system can be used on single and multi-track railway lines, where the maximum train speed does not exceed $160 \mathrm{~km} / \mathrm{h}$, [9].

\section{System modeling}

One of the ways of obtaining information on system safety parameters is mathematical modeling. Fig. 4 presents a mathematical model including radio transmission in the system of automatic level crossing, [7].

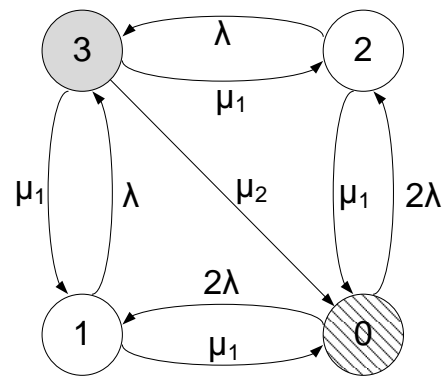

Fig. 4: Model with radio transmissions (own study)

In this model, we can distinguish states:

- 0 - the state of correct work. Data transmission takes place through both channels,

- 1 - damage condition of the first channel,

- 2 - damage condition of the second channel,

- 3 - damage condition of both channels.

Both the first and the second states are responsible for the lack of transmission in a given channel. Due to the doubled channel structure, in the event of transmission failure in one of them, the second channel allows the system to continue to operate in the damaged state of the control [3]. State 3 is responsible for the failure of both 
transmission channels. In this state, the devices are replaced. For the model in Figure 4, we can write the following state equations:

$$
\left\{\begin{array}{l}
\frac{d P_{0}}{d t}=-4 \lambda P_{0}(t)+\mu_{1} P_{1}(t)+\mu_{1} P_{2}(t)+\mu_{2} P_{3}(t) \\
\frac{d P_{1}}{d t}=2 \lambda P_{0}(t)-\lambda P_{1}(t)-\mu_{1} P_{1}(t) \\
\frac{d P_{2}}{d t}=2 \lambda P_{0}(t)-\lambda P_{2}(t)-\mu_{1} P_{2}(t) \\
\frac{d P_{3}}{d t}=\lambda P_{1}(t)+\lambda P_{2}(t)-\mu_{2} P_{3}(t)
\end{array}\right.
$$

Parameters $\lambda$ and $\mu$ describe respectively:

- $\lambda$ - intensity of damages to the radio modem (including suspension, stopping the system),

- $\mu$ - return to full efficiency (e.g. reset of a radio modem).

For the analysis, a reliability parameter was proposed in the form of the availability expressed by the formula, [3]:

$$
A=\lim _{t \rightarrow \infty} \sum_{i} P_{i}(t)
$$

where $i$ is associated with the states of correct work.

Assuming parameters $\lambda$ and $\mu$ :

- $\lambda=1.2 \mathrm{E}-06 \mathrm{~h}^{-1}$

- $\quad \mu_{1}=1 / \mathrm{t}-$ which corresponds to the length of the device reset time after stopping $(\sim 1 \mathrm{~min}$.),

- $\quad \mu_{2}=1 / \mathrm{t}$ - which corresponds to time of repair, and using the Mathematica application, Fig. 5,

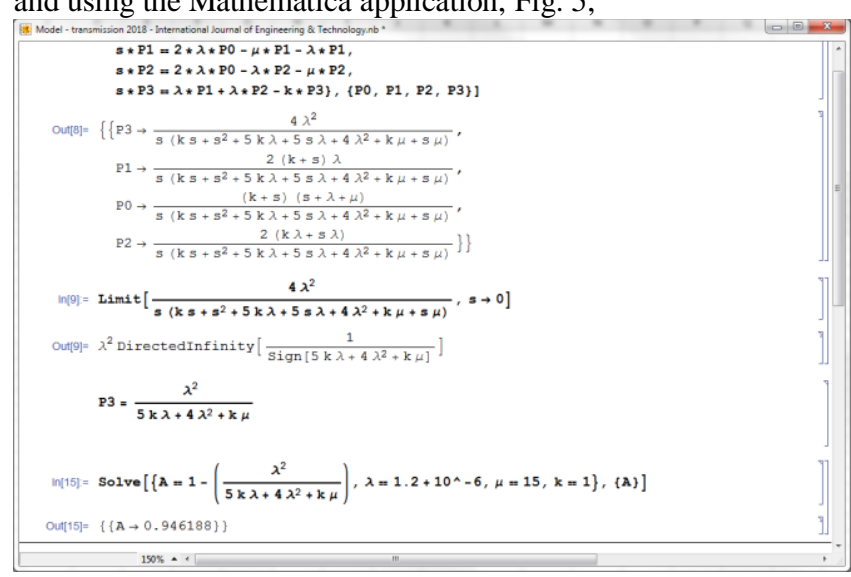

Fig. 5: Calculations in the Mathematica software (own study)

calculated values the availability $\mathrm{A}(\mathrm{t})_{\mathrm{t} \rightarrow \infty}$ with reference to time of modem repair/change (failure of two channels) are presented in the Table 2.

Table 2: The value of availability in a function of reset time

\begin{tabular}{|c|c|c|}
\hline No. & Time of repair / change & Availability \\
\hline 1 & $10 \mathrm{~min}$ & 0.989 \\
\hline 2 & $30 \mathrm{~min}$ & 0.9698 \\
\hline 3 & $1 \mathrm{~h}$ & 0.94618 \\
\hline 4 & $5 \mathrm{~h}$ & 0.85542 \\
\hline 5 & $10 \mathrm{~h}$ & 0.81679 \\
\hline 6 & $20 \mathrm{~h}$ & 0.78854 \\
\hline
\end{tabular}

\section{Verification Based on Statistical Data}

$\chi 2$ test was used in order to carry out the analysis of RASP-4F system. The calculations are based on statistical data and are shown in tables 3 and 4 [8].
Table 3: Calculations for the system

\begin{tabular}{|c|c|c|c|c|c|}
\hline No. & \multicolumn{2}{|c|}{$\left\langle\mathbf{t}_{\mathbf{i}}{ }^{\prime}, \mathbf{t}_{\mathbf{i}}{ }^{\prime \prime}\right)$} & $\mathbf{t}_{\mathbf{i s r}}$ & $\mathbf{n}_{\mathbf{i}}$ & $\mathbf{F}\left(\mathbf{t}_{\mathbf{i}}{ }^{\prime \prime}\right)$ \\
\hline 1 & 0 & 9000 & 4500 & 5 & 0.486582881 \\
\hline 2 & 9000 & 18000 & 13500 & 6 & 0.736402862 \\
\hline 3 & 18000 & 27000 & 22500 & 5 & 0.864664717 \\
\hline SUM & & & & $\mathbf{1 6}$ & \\
\hline
\end{tabular}

Table 4: Calculations for the system

\begin{tabular}{|c|c|c|c|c|}
\hline No. & $\mathbf{p}_{\mathbf{i}}$ & $\mathbf{n p}_{\mathbf{i}}$ & $\left(\mathbf{n}_{\mathbf{i}}-\mathbf{n}_{\mathbf{p i}}\right)^{\mathbf{2}}$ & $\left(\mathbf{n}_{\mathbf{i}}-\mathbf{n}_{\mathbf{p} \mathbf{i}}\right)^{\mathbf{2}} / \mathbf{n p}_{\mathbf{i}}$ \\
\hline 1 & 0.48658288 & 7.78532609 & 7.75804146 & 0.99649538 \\
\hline 2 & 0.24981998 & 3.99711969 & 4.01152952 & 1.00360505 \\
\hline 3 & 0.26359714 & 4.21755421 & 0.61222142 & 0.14516029 \\
\hline SUM & $\mathbf{1}$ & & & $\mathbf{2 . 1 4 5 2 6 0 7 2}$ \\
\hline
\end{tabular}

Probabilities of $p_{i}$ were calculated according to:

$$
p_{1}=F\left(t_{1}^{\prime \prime}\right)
$$$$
p_{2}=F\left(t_{2}^{\prime \prime}\right)
$$

$p_{3}=1-\left(F\left(t_{1}^{\prime \prime}\right)+F\left(t_{2}^{\prime \prime}\right)\right)$

Due to the fact, that:

$$
\sum_{i=1}^{r} p_{i}=1
$$

the values of cumulative distribution in individual ranges were calculated on the basis of the formula:

$$
F\left(t^{\prime \prime}\right)=1-\exp ^{\left(-\lambda \cdot t_{i}^{\prime \prime}\right)}
$$

Intensity of failure in the exponential distribution parameter was calculated based on the formula:

$$
\lambda=\frac{n}{\sum_{i=1}^{r} n_{i} t_{i s r}}=\frac{16}{5 \cdot 4500+6 \cdot 13500+5 \cdot 22500}=7,40741 \cdot 10^{-5} \mathrm{~h}^{-1}
$$

The distribution quantile for the limit significance level based on the distribution tables is:

$\chi_{r-1-v}^{2}=\chi^{2}{ }_{1,0.95}=3,841$

Since:

$\chi_{\text {emp }}^{2}=2,145<\chi_{1,0.95}^{2}=3,841$

therefore, there is no reason to reject the hypothesis, that the failure times for the analyzed group of systems are related to the exponential distribution. Assuming a reaction time $t_{d A}=t_{d B}=1 \mathrm{~s}$., based on formula (2), the value of the calculated THR index is:

$\mathrm{THR}=3,047 \mathrm{E}-12$

(value for SIL4: 10E-9 $\leq$ THR $\leq 10 \mathrm{E}-8$ )

\section{Conclusions}

Modern systems of automatic level crossing systems belong to the group of safe devices. Unfortunately, there are collisions at railway crossings, but in most cases, through fault of the drivers of motor vehicles. Accidents on the intersection of road and railway crossing in Poland constitute about $0.8 \%$ of the total number of road accidents. The presented analysis proves that the level crossing system described in the paper meet the requirements of standards, including SIL-4. This has been achieved due to the use of appropriate hardware solutions, including redundancy at the hard- 
ware level. Proposed in the paper the analysis in the form of the Markov process is one of the recommended methods of railway automation systems analysis, [6]. The modeling and analysis of railway automation systems can be a part of another research issue taking into account to the influence of electromagnetic interference on rail computer systems reliability [11].

\section{References}

[1] Report 2016 of PKP Polish Railway Lines SA

[2] PN-EN 50126-2 standard.

[3] Ukleja P., Perzyński T.: „The possibility to apply the radio transmission along the railway". TTS 12/2015. CD, pp. 2996-2999.

[4] Lewiński A., Perzyński T. „Nowoczesne systemy sterowania ruchem kolejowym". Inżynier Budownictwa, Volume 7/8 2014, pp. 48-55. ISSN 1732-3428.

[5] Perzyński T.: „The problems of safety of computer networks applied in the railway traffic control". PhD dissertation - Technical University of Radom, Faculty of Electric Engineering and Transport, Radom 2009.

[6] Nowakowski W., Lukasik Z., Bojarczak, P. "Technical safety in the process of globalization". 16th International Scientific Conference on Globalization and its Socio-Economic Consequences. Rajecke Teplice, Slovakia 2016. Proceedings, Part IV, pp. 1571-1578.

[7] Lewiński A, Perzyński T., Ukleja P.: „Possibility of use the wireless communication in protection of rail traffic on the regional line". Scientific journal "Problemy Kolejnictwa, Volume 175/2017, ISSN 0552-2145, pp. 53-58

[8] Lewiński A., Perzyńśki T., Bester L.:" Computer aided safety analysis of railway control systems". Journal of KONBiN 2(26)2013, pp. 137-150.

[9] www.kombud.com.pl (10-05-2018).

[10] CENELEC - EN 50129. Railway Applications Communication, Signalling and Processing Systems Safety Related Electronic Systems for Signalling.

[11] Siergiejczyk M, Pas J., Rosinski A.: "Issue of reliabilityexploitation evaluation of electronic transport systems used in the railway environment with consideration of electromagnetic interference". IET Intelligent Transport Systems, Volume 10, Issue 9 November 2016,. $587-593$. 